\title{
A mini review on production of pluripotency factors (Oct4, Sox2, Klf4 and c-Myc) through recombinant protein technology
}

\author{
David Septian Sumanto Marpaung ${ }^{a *}$, Ayu Oshin Yap Sinaga ${ }^{\mathrm{b}}$ \\ ${ }^{a}$ Department of Biosystems Engineering, Institut Teknologi Sumatera, South Lampung 35365, Indonesia \\ ${ }^{b}$ Department of Biology, Institut Teknologi Sumatera, South Lampung 35365, Indonesia
}

Article history:

Received: 14 April 2020 / Received in revised form: 13 May 2020 / Accepted: 14 May 2020

\begin{abstract}
The four transcription factors Oct4, Sox2, Klf4 and c-Myc are highly expressed in embryonic stem cells (ESC) and their overexpression can induce pluripotency, an ability to differentiate into all cell types of an organism. The ectopic expression such transcription factors could reprogram somatic stem cells to be induced pluripotency stem cells (iPSC), an embryonic stem cells-like. The production of recombinant pluripotency factors gain interests due to the high demand from the generation of induced pluripotent stem cells in regenerative medical therapy recently. The focus of review is to demonstrate the recent advances in recombinant pluripotency factor production using various hosts.
\end{abstract}

Keywords: Stem cell, transcription factor, recombinant protein, induced pluripotent stem cells

\section{Introduction}

The recent advances of medical technologies are vastly contributed to raise the life expectancy of human. The development of novel regenerative therapy has created a new insight to cope with the problem in the increasing frequency of various diseases. An ability to differentiate into another cell type, known as pluripotency, in the beginning was only known to be occurred in embryonic stem cells and it allowed the scientist to develop new organ for regenerative therapies. [1]. Embryonic stem cells are the pluripotent stem cells derived from the inner cell mass of a blastocyst, known as a tool for regenerative medical therapy. However, there are several ethical issues regarding the use of human embryos and the problem of tissue rejection following transplantation in patients. Since the phenomenal invention by Takahashi and Yamanaka in 2006, the generation of pluripotent stem cells from somatic stem cells using transcription factor has opened a new insight in stem cells research. The first person to receive 'reprogrammed' stem cells from another person is a Japanese man. The donor's iPS cells were transformed into retinal cells and transplanted into a patient [21]. Another case of pluripotent stem cells use is also found to treat blood diseases and ophthalmic diseases [22]. A series of clinical studies are prepared for the applications of therapeutic derivatives of PSCs applied in medical therapy such as, agerelated macular degeneration, Parkinson disease, spinal cord injury, diabetes and myocardial infarction [2].

* Corresponding author.

Email: david.marpaung@tbs.itera.ac.id
In the process to find the factor of pluripotency of stem cells, Takahashi and Yamanaka selected 24 genes as the candidates for factors that induced pluripotency in somatic cells, and it resulted in the four transcription factors (Oct3/4, Sox2, c-Myc, and Klf4) that were able to induce pluripotent stem cells from mouse embryonic or adult fibroblasts to be the pluripotent cells under embryonic stem cell culture condition [3]. Transcription factor is a group of proteins control gene expression by binding to regulatory DNA sequences inside cell genome and mobilize RNA polymerase and cofactors to target genes, resulting in transcription initiation. In other word, the four pluripotency factors are the regulatory key to generate pluripotency and differentiation of stem cells.

Several methods have been used for the generation of induced pluripotent stem cells. In most cases, the transcription factors have been generated using retroviral transduction. The insertion at large number of sites in the host genome and promotion in the expression of oncogenes or disrupt tumor suppressor genes can be done by retroviral vector DNAs [4]. The limitation of that method, however, is related to the risk of insertional mutagenesis of the genome-integrating. There are several protocols that have been explored to minimize or avoid the side effects resulting from exogenous DNA integration with potentially reduced risks including the substitution of the retrovirus vector with adenovirus vector [5], PiggyBac and sleeping beauty transposon systems [6], Sendai viruses [7], synthetic modified mRNA [8] and small molecule drugs [9]. While such methods could reduce the risk of insertional mutagenesis, nucleic-free approaches are considered as highly desirable in the potential clinical 
applications of iPSC. In addition, direct reprogramming proteins have been also successfully introduced the transcription factors and generated iPSC [10,11]. The direct reprogramming protein systems needs more a concern due to the expression of transcription factors is under control of regulatory protein and it requires an accurate regulation to maintain the stem cell. A narrow change of proteins amount can totally affect to cell fate that eventually cause tumorigenesis. For instance, Stefanovic and Puceat in 2007 reported that Oct 4 was not only as an inducer for pluripotency stem cells but also as something crucial for cell fate transitions and embryonic development [12]. There is a strict regulation for amount of Oct4 protein to induce pluripotency in somatic stem cells. The stem cells will lose their pluripotency and start differentiation into endoderm and mesoderm when Oct 4 protein is elevated more than 2 -fold compared to normal conditions [13]. Therefore, the regulation of pluripotency by recombinant protein is convenience manner due to the simple control of pluripotency factors amount. In addition, pluripotency factors produced through recombinant protein technology can give higher yield than other methods. In this review, we focused on the discussions about the production of pluripotency factors through recombinant protein technology.

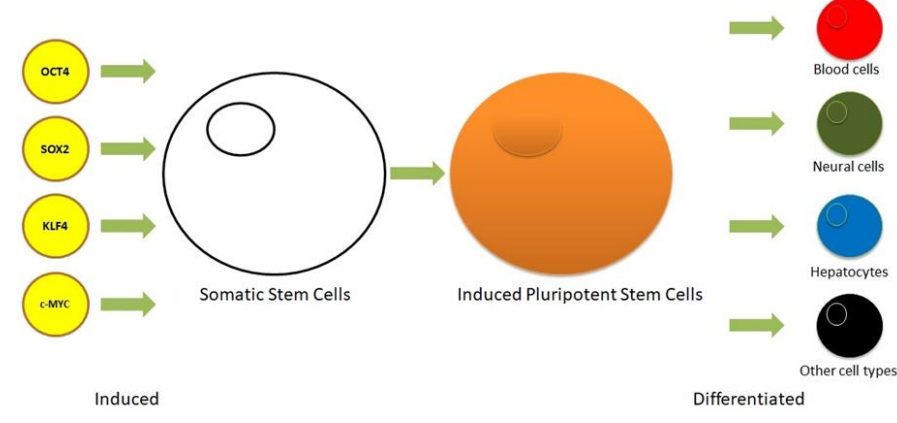

Fig 1 Schematic representation of induced pluripotent stem cells from somatic stem cells

\section{Recombinant Pluripotency Factor Production}

Recombinant protein drugs are required for both therapy for the long periods and disease treatment. The technology for the production of human protein will continuously be developed to be used in a variety of human disease treatments [14]. Stanley Cohen and Herber Boyer in 1973 were the first persons to initiate what was later coined recombinant technology [15]. They isolated human DNA and copied it into a bacterial plasmid, resulting in this genetically engineered bacterium producing a foreign protein. From a pharmaceutical perspective, this successful recombinant DNA experiment led the possibility to generate human biomolecules in any other organisms. Recently there are several hosts to produce recombinant protein such as bacteria, fungi, plant cells, insect cells and mammalian cells. The common types of recombinant human protein produced are human serum, human antibodies, human growth factor, human proteases and human enzymes. Production recombinant human transcription factor brought the new challenges in recombinant protein research, due to its function only appear inside nucleus. The common strategy to produce recombinant pluripotency factors includes plasmid construction, optimization cell growth, protein purification, intracellular delivery and biological activity treatment will be applied. To date, recombinant pluripotent transcription factor was expressed in several host includes, $E$. coli $[10,16]$, Baculovirus-infected Sf9 insect cells [17], Pichia pastoris [18] and mammalian cells [11].

There are several hosts have been expressed the four pluripotent transcription factors such as, E. coli, baculovirusinfected Sf9 insect cells, Pichia pastoris and mammalian cells (Table 1). To date, $60-70 \%$ of all recombinant protein pharmaceuticals are still produced in mammalian cell lines despite relatively high production costs and difficult in handling. Kim and colleagues demonstrated direct reprogramming of human fetal fibroblasts by the treatment of cell extracts from HEK293 cells which expressed each transcription factor fused to eight arginine residues (8R). Another host to express recombinant Oct4, Sox2, Klf4 and cMyc proteins were E. coli and reprogramed OG2/Oct4-GFP reporter fused MEF cells with four cycles of protein treatments plus the histone deacetylase (HDAC) inhibitor, valproic acid (VPA) [10]. The four recombinant proteins were also expressed fused to SUMO tag, a short polypeptide sequence derived from the HIV trans-activator of transcription protein (TAT), nuclear localization signal (NLS) and the $E$. coli bacteria containing chaperones, which able decrease the misfolding of these proteins [16]. The E. coli expression system is gained a high yield of target proteins in a short time with low cost and the simple protein purification process. However, the recombinant protein must be released from the inclusion bodies under denaturing conditions in $E$. coli expression system [10]. Baculovirus-infected Sf9 insect cells also can be a good host to produce the recombinant transcription factor of pluripotent stem cells. Unfortunately, secreted proteins are unable to be found, and all of them are detected only in the cell debris. This characteristic of these proteins has made their utility limited and resulted in low yield protein [17]. Meanwhile, the high yield Oct4 production as shown in $P$. pastoris expression system relies on the AOX1 promoter (PAOX1) which is strongly induced by methanol [18]. However, the toxic and inflammatory nature of methanol restricts its application in edible and medical products, and the biological activity is necessary attempted [19].
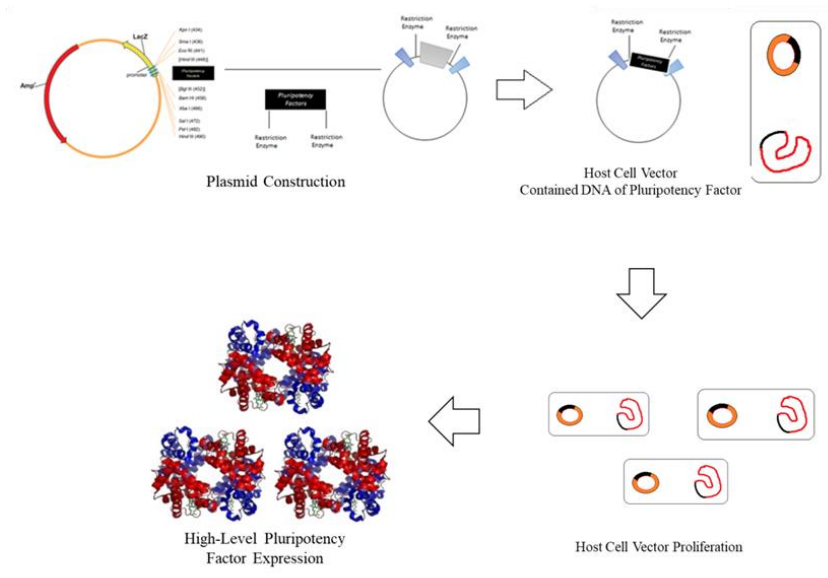

Fig 2 Strategy of production pluripotency factors through recombinant protein technology 


\section{Intracellular Delivery of Recombinant Pluripotency Factors}

The four pluripotency factors are the key regulatory transcription factor of pluripotent stem cells in which protein is located inside nucleus. As the transcription factor, they need to be delivered from outside cells into nucleus. Major challenge for the intracellular delivery of recombinant proteins is their limited ability to cross the cell membrane. An ideal protein transduction method has to fulfill several criteria and (1) stabilize the recombinant protein, (2) facilitate its cellular entry and endosomal escape, (3) allow cell treatment with sufficient protein concentrations and (4) provide sustained protein levels without the need for any repeated treatments [20]. In most research about recombinant pluripotency production, they fused the transcription factor with cell penetrating peptide (CPP). Although some researchers have distinguished their term, another common protein delivery is also called as protein transduction domain (PTD) [23]. CPP fused with various small molecules can translocate across cell membranes via receptor-mediated endocytosis [24]. The mechanism of CPP across the cell membrane is showed in Fig 3. In the time before reprogramming issues well-known, there are a dozen articles talked about the delivery of transcription factor in cells [25]. However, the inspiring invention from Takahashi and Yamanaka opened some opportunities for new pluripotency factor applications and promoted the rapid growth of articles devoted to deliver different transcription factor fused with CPP. Trans-Activator of Transcription protein (TAT) derived from HIV virus [26] and polyarginines as well as arginine rich sequences [27] are the most popular CPPs used in researches.

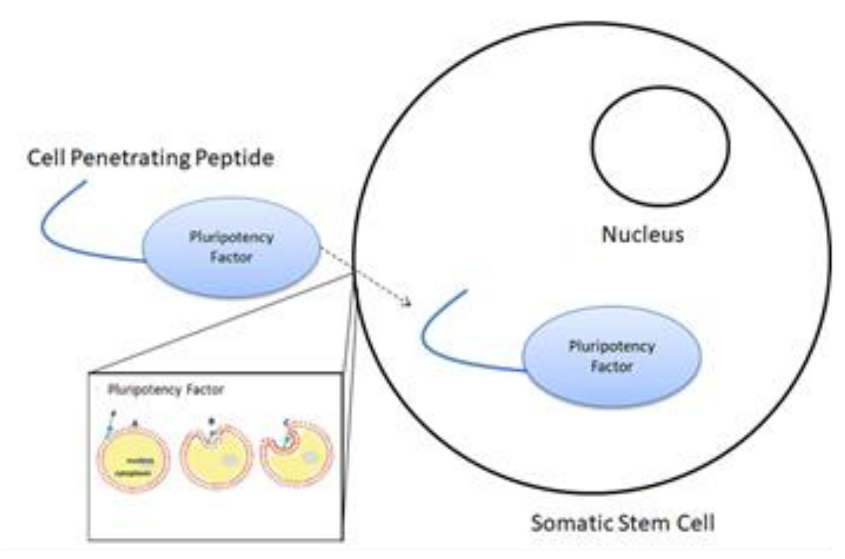

Fig 3 Mechanism of pluripotency factor fused with cell penetrating peptide across cell membrane

The delivery of recombinant pluripotency factor using TAT has been reported terribly slow $(\approx 8$ weeks) and inefficient $(\approx 0.001 \%$ reprogramming rate) compared to retrovirus-based methods ( $\approx 0.01 \%$ of input cells) $[10,11]$. The low stability and solubility of recombinant pluripotency factors and poor endosomal release presumably caused the low success of stem cell generation. Beside fused recombinant pluripotency factors with CPP, some researchers also used nanoparticles approaches for intracellular delivery. One of nanoparticles, chitosan, offers promising tool to deliver recombinant pluripotency across cell membrane. Chitosan is the cationic polymers which adhere to negatively charged cell surface, through their cellular uptake by endocytosis [28]. Recombinant pluripotency factors from Baculovirus-infected Sf9 insect cells are delivered using chitosan nanoparticle [20]. The encapsulation of Oct4 in nuclear-targeted chitosan strongly stabilizes its DNA-binding activity compared to the soluble Oct4 protein. The Oct4-loaded chitosan successfully delivers active Oct4 into human fibroblasts. Further development of the utility of pluripotency factors in proteinbased iPSC generation is necessary.

Table 1. Pluripotency factors produced through recombinant protein technology

\begin{tabular}{|c|c|c|c|c|}
\hline $\begin{array}{c}\text { Recombinant } \\
\text { Protein } \\
\text { production } \\
\text { system } \\
\end{array}$ & Host & $\begin{array}{l}\text { Biological } \\
\text { activity }\end{array}$ & $\begin{array}{c}\text { Intracellular } \\
\text { delivery }\end{array}$ & Reference \\
\hline $\begin{array}{l}\text { Mammalian } \\
\text { cells }\end{array}$ & $\begin{array}{c}\text { HEK } \\
\text { (Human } \\
\text { embryonic } \\
\text { kidney) } \\
293 \text { cells }\end{array}$ & $\begin{array}{c}\text { Generated } \\
\text { induced } \\
\text { pluripotent } \\
\text { stem cells }\end{array}$ & 9 arginine & [11] \\
\hline Insect cells & $\begin{array}{c}\text { Sodoptera } \\
\text { frugiperda } \\
\text { (SF9) }\end{array}$ & $\begin{array}{c}\text { The } \\
\text { pluripotency } \\
\text { factor } \\
\text { penetrated } \\
\text { cell } \\
\text { membrane }\end{array}$ & $\begin{array}{c}\text { Nanoparticle } \\
\text { chitosan }\end{array}$ & {$[17,20]$} \\
\hline Bacteria & E. coli & $\begin{array}{c}\text { Generated } \\
\text { induced } \\
\text { pluripotent } \\
\text { stem cells }\end{array}$ & $\begin{array}{l}11 \text { arginine; } \\
\text { TAT peptide } \\
\text { fused with } \\
\text { SUMO }\end{array}$ & {$[10,16]$} \\
\hline Fungi & P. pastoris & $\begin{array}{c}\text { The } \\
\text { pluripotency } \\
\text { factor } \\
\text { penetrated } \\
\text { cell } \\
\text { membrane }\end{array}$ & Tat $47-57$ & [18] \\
\hline
\end{tabular}

\section{Conclusion}

Induced pluripotent stem cells (iPSCs) offer an ideal cell source for future regenerative therapies. The strict regulation of pluripotency factors induction in cells will be solved using recombinant protein technology. Recombinant protein technology is the most promising and realistic technology now to generate induced pluripotent stem cells in virus-free and transgene-free human patient specific iPSC. To date, recombinant pluripotent transcription factor are expressed in several hosts including, E. coli, baculovirus-infected Sf9 insect cells, Pichia pastoris and mammalian cells. Other host, such as plant cells, would be interested to be attempted to produce recombinant pluripotency factors, since it was known as the safest and economically host recombinant protein production. The clinical trial of recombinant pluripotency 
factor from each host is necessary to be developed further for medical treatment application.

\section{Acknowledgements}

The author would like thanks to Graduate School of Biotechnology and Bioengineering, Yuan Ze University, Taiwan.

\section{References}

1. B. V. Johnson, N. Shindo, P. D. Rathjen, J. Rathjen, and R. A. Keough, Understanding pluripotency-how embryonic stem cells keep their options open, Mol. Hum. Reprod. 14 (2008) 513-520.

2. A. Trounson, N. D. DeWitt, Pluripotent stem cells progressing to the clinic, Nat. Rev. Mol. Cell Biol. 17 (2016) 194-200.

3. K. Takahashi, S. Yamanaka, Induction of pluripotent stem cells from mouse embryonic and adult fibroblast cultures by defined factors, Cell 126 (2006) 663-676.

4. S. Ruiz, O. Fernandez-Capetillo, Reducing genomic instability in iPSCs, Oncotarget. 6 (2015) 34045-34046.

5. A. Harui, S. Suzuki, S. Kochanek, and K. Mitani, Frequency and stability of chromosomal integration of adenovirus vectors, J. Virol. 73 (1999) 6141-6146.

6. K.Woltjen, I. P. Michael, P. Mohseni, R. Desai, M. Mileikovsky, R. Hamalainen, et al., piggyBac transposition reprograms fibroblasts to induced pluripotent stem cells, Nature 458 (2009) 766-770.

7. H. Ban, N. Nishishita, N. Fusaki, T. Tabata, K. Saeki, M. Shikamura, et al., Efficient generation of transgene-free human induced pluripotent stem cells (iPSCs) by temperature-sensitive Sendai virus vectors, Proc. Natl. Acad. Sci. 108 (2011) 1423414239.

8. L. Warren, P. D. Manos, T. Ahfeldt, Y. H. Loh, H. Li, F. Lau., et al., Highly efficient reprogramming to pluripotency and directed differentiation of human cells with synthetic modified mRNA, Cell Stem Cell 7 (2010) 618-630.

9. P. Hou, Y. Li, X. Zhang, C. Liu, J. Guan, H. Li, et al., Pluripotent stem cells induced from mouse somatic cells by small-molecule compounds, Science 341 (2013) 651-654

10. H. Y. Zhou, S. L. Wu, J. Y. Joo, S. Y. Zhu, D. W. Han, T. X. Lin, et al., Generation of induced pluripotent stem cells using recombinant proteins, Cell Stem Cell 4 (2009) 381-384.

11. D. Kim, C.-H. Kim, J.-I. Moon, Y.-G. Chung, M.-Y. Chang, B.-S. Han, et al., Generation of human induced pluripotent stem cells by direct delivery of reprogramming proteins, Cell Stem Cell 4 (2009) 472-476.

12. S. Stefanovic, M. Pucéat, Oct-3/4: Not just a gatekeeper of pluripotency for embryonic stem cell, a cell fate instructor through a gene dosage effect, Cell Cycle 6 (2007) 8-10.

13. H. Niwa, J. Miyazaki, A. G. Smith, Quantitative expression of Oct-
3/4 defines differentiation, dedifferentiation or self-renewal of ES cells, Nat. Genet. 24 (2000) 372-376.

14. T. Dingermann, Recombinant therapeutic proteins: Production platforms and challenges, Biotechnol. J. 3 (2008) 90-97.

15. S. N. Cohen, A. C. Chang, H. W. Boyer, R. B. Helling, Construction of biologically functional bacterial plasmids in vitro, Proc. Natl. Acad. Sci. USA 70 (1973) 3240-3244

16. G.-D. Liu, S.-F. Zhou, X.-C. Ding, C.-L. Fang, S.-Y. Mi, X.-C. Gao, Soluble expression of recombinant cMyc, Klf4, Oct4, and Sox2 proteins in bacteria and transduction into living cells, Int. J. Ophthalmol. 10 (2017) 560-566.

17. P. N. Malak, B. Dannenmann, A. Hirth, O. C. Rothfuss, K. SchulzeOsthoff, Novel AKT phosphorylation sites identified in the pluripotency factors Oct4, Sox 2 and Klf4, Cell Cycle 14 (2015) 3748-3754.

18. H. Wang, X. Zhang, N. Kong, A. Wei, Y. Zhang, J. Ma, et al, Expression, purification and characterization of a recombinant Tat47-57-Oct4 fusion protein in Pichia pastoris, Mol. Med. Rep. 9 (2014) 471-475.

19. W. Shen, Y. Xue, Y. Liu, C. Kong, X. Wang, M. Huang, A novel methanol-free Pichia pastoris system for recombinant protein expression, Microb. Cell Fact. 15 (2016) 178.

20. S. Tammam, P. Malak, D. Correa, O. Rothfuss, H. M. E. Azzazy, A. Lamprecht, et al., Nuclear delivery of recombinant Oct4 by chitosan nanoparticles for transgene-free generation of protein-induced pluripotent stem cells, Oncotarget. 7 (2016) 37728-37739.

21. D. Cyranoski, Japanese man is first to receive 'reprogrammed' stem cells from another person, Nature News. (2017) Available: https://www.nature.com/news/japanese-man-is-first-to-receivereprogrammed-stem-cells-from-another-person-1.21730 [Accesed: 4-Feb-2020].

22. U. Martin, Therapeutic application of pluripotent stem cells: Challenges and risks, Fron. Med. 4 (2017) 229

23. S. Miersch, S. S. Sidhu, Intracellular targeting with engineered proteins, F1000Research 5 (2016) 1947.

24. E. Koren, V. P. Torchilin, Cell-penetrating peptides: breaking through to the other side, Trends Mol. Med. 18 (2012) 385-393.

25. A. V. Ulasov, A. A. Rosenkranz, A. S. Sobolev, Transcription factors: Time to deliver, J. Control. Release 269 (2018) 24-35

26. A. D. Frankel, C. O. Pabo, Cellular uptake of the tat protein from human immunodeficiency virus, Cell 55 (1988) 1189-1193

27. S. Futaki, T. Suzuki, W. Ohashi, T. Yagami, S. Tanaka, K. Ueda, Y. Sugiura, Arginine-rich peptides: An abundant source of membranepermeable peptides having potential as carriers for intracellular protein delivery, J. Biol. Chem. 276 (2001) 5836-5840.

28. O. Harush-Frenkel, N. Debotton, S. Benita, Y. Altschuler, Targeting of nanoparticles to the clathrin-mediated endocytic pathway, Biochem. Biophys. Res. Commun. 353 (2007) 26-32. 